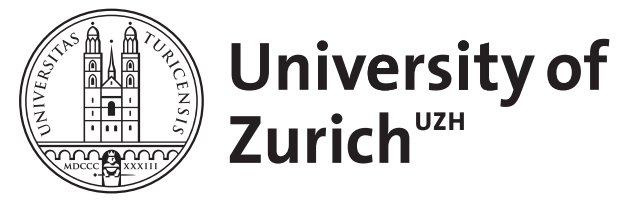

\title{
Malignant disease of the larynx and pharynx (Second communication)
}

Zuppinger, A ; Stewart-Harrison, R

DOI: https://doi.org/10.1017/s0022215100040792

Posted at the Zurich Open Repository and Archive, University of Zurich

ZORA URL: https://doi.org/10.5167/uzh-155303

Journal Article

Published Version

Originally published at:

Zuppinger, A; Stewart-Harrison, R (1934). Malignant disease of the larynx and pharynx (Second communication). Journal of Laryngology and Otology, 49(11):720-732.

DOI: https://doi.org/10.1017/s0022215100040792 


\section{MALIGNANT DISEASE OF THE LARYNX AND PHARYNX (SECOND COMMUNICATION)}

By A. ZUPPINGER and R. STEWART-HARRISON (Zürich) (From the University Röntgeninstitut Zürich (Prof. Dr. H. R. Schinz))

THE very disappointing results that had been obtained in Zürich from the usual surgical and radiological treatment of malignant disease of the upper air passages led to the adoption, in 1929 , of the principles stated by Coutard in the X-ray treatment of these neoplasms. One of the authors (A. Z.) studied the method with Coutard in Paris and introduced it to Zürich. Since then this technique has been developed and elaborated under the name protracted-fractional X-ray treatment (Schinz). In 1932 one of the authors (R. S.-H.) made a report on the technique and results of this form of treatment and published it as a first communication with the above title in this Journal in November, 1932 .

This first communication gave the results of the protractedfractional treatment of 144 cases of malignant disease of the larynx and pharynx. The cases had been observed for a period of three-quarters to two and a half years after treatment. The author was careful to point out that the first communication was purely provisional : he saw its justification in the fact that it would render a further investigation of the technique, which was considered to be promising, possible. We are now in a position to supplement the first communication with a second : this, also, is of a provisional nature and deals with the results of treatment after a period of observation varying from two and a half to five years. The five year rates which are indispensable for the final evaluation of technique in the treatment of cancer must wait until sufficient material has been collected and until sufficient time has elapsed.

The present material, consisting of the first 159 cases treated, is practically identical with the $\mathbf{I} 44$ cases dealt with in the first communication. The last case reviewed concluded 


\section{Malignant Disease of Larynx and Pharynx}

treatment on April Ist, 1932. The former report covered the cases up to January Ist, I932. The slight difference in material (I5 cases) is due to technical circumstances and does not prevent this report from being considered as a "follow-up" of the material of the original communication.

The character of the material was also described in detail in the first communication. The fact that this Institute is not in a position to select its material has led to a large proportion of very advanced cases. In more than half, the primary tumour was completely inoperable when first seen, even when excision of the larynx and resection of the pharynx is regarded as a practicable operation. Considering the cases of malignant disease of the pharynx separately, only 9 per cent. showed an operable primary tumour in association with operable metastases. The difficulties offered by the material are shown in Table I.

TABLE I.

\begin{tabular}{|c|c|c|c|c|}
\hline & $\begin{array}{l}\text { Total } \\
\text { cases. }\end{array}$ & $\begin{array}{c}\text { Primary } \\
\text { tumour } \\
\text { operable } \\
\text { in } \%\end{array}$ & $\begin{array}{l}\text { Cases with no } \\
\text { metastases } \\
\text { in } \%\end{array}$ & $\begin{array}{l}\text { Primary tumour } \\
\text { operable and no } \\
\text { metastases in } \%\end{array}$ \\
\hline Epipharynx & 6 & o & o & 0 \\
\hline Mesopharynx & 66 & I I & $2 \mathbf{I}$ & 6 \\
\hline Hypopharynx & 72 & 8 & I6 & 4 \\
\hline Intrinsic Larynx & I 5 & 60 & 80 & 60 \\
\hline Total & I 59 & $I_{4}$ & 24 & I0 \\
\hline
\end{tabular}

In Tables II and III the two-year results are shown. For purposes of comparison, the corresponding tables from the first communication are reproduced (Tables II $a$ and III $a$ ). Two changes will be noticed in the compilation of the two tables. In the new table we have dropped the column $\mathrm{C}$, "Initially Free from Symptoms, Primary and Regional". Experience has taught us that the determination of " SymptomFree" during the first weeks after treatment is impossible. Secondly, column $\mathrm{F}$ has undergone a subdivision corresponding to the increase of the observation time to two and a half years. In column $F_{1}$ the cases which died of intercurrent disease by proven freedom from cancer more than one year after treatment are shown. Column $\mathrm{F}_{2}$ shows the cases which died during the first year after treatment of intercurrent disease. The local 


\section{A. Zuppinger and R. Stewart-Harrison}

TABLE II. (Compiled Sept., 1934.)

\begin{tabular}{|c|c|c|c|c|c|c|c|c|}
\hline & A. & B. & $\mathrm{D}$. & E. & $F_{\mathbf{I}}$. & $\mathbf{F}_{2}$ & G. & H. \\
\hline & $\underset{\mathrm{g}}{\mathrm{j}}$ & 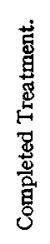 & 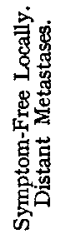 & 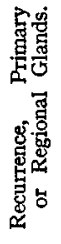 & 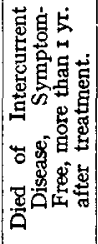 & 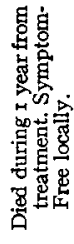 & 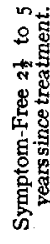 & 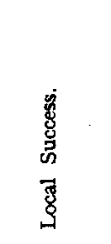 \\
\hline Epipharynx & 6 & 5 & 2 & - & $\mathbf{I}$ & - & 2 & $5: 5$ \\
\hline Tonsil & 29 & 22 & 4 & 2 & - & 3 & 7 & I4:22* \\
\hline Base of the tongue & 19 & I5 & I & I & - & 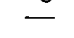 & 4 & $6: 15$ \\
\hline Vallecula $\ldots \quad \ldots \quad \ldots$ & 13 & 12 & 4 & 5 & I & $\mathbf{I}$ & I & $6: 12$ \\
\hline $\begin{array}{l}\text { Lateral and posterior wall, } \\
\text { mesopharynx }\end{array}$ & 5 & 2 & $\sigma$ & $\mathbf{T}$ & - & 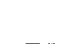 & 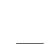 & 0.2 \\
\hline $\begin{array}{ll}\text { Epiglottis } & \ldots\end{array}$ & $\begin{array}{l}3 \\
4\end{array}$ & 3 & I & 2 & - & - & 二 & $x: 3$ \\
\hline Aryepiglottic fold & 9 & 9 & 3 & & $\mathbf{I}$ & 2 & 2 & $7: 9$ \\
\hline Arytenoid .. .. & 4 & 3 & I & 一 & $\mathbf{r}$ & 二 & I & $3: 3$ \\
\hline Sinus pyriformis $\ldots$ & $4 \mathrm{I}$ & 30 & 8 & 2 & 7 & $\mathbf{I}$ & 4 & $13: 30$ \\
\hline $\begin{array}{l}\text { Postcricoid } \\
\text { Extensive hypopharyngeal }\end{array}$ & 5 & 3 & - & I & & 一 & I & $1: 3$ \\
\hline $\begin{array}{c}\text { Extensive hypopharyngeal } \\
\text { growth } \ldots\end{array}$ & 9 & 6 & I & - & 2 & $\mathbf{I}$ & - & $2: 6$ \\
\hline Intrinsic laryngeal & $\begin{array}{l}9 \\
15\end{array}$ & Io & - & I & I & $\mathbf{I}$ & 5 & $6: 10$ \\
\hline
\end{tabular}

* Including 6 cases of Sarcoma of the Tonsil.

TABLE IIa. (Compiled Sept., 1932.)

\begin{tabular}{|c|c|c|c|c|c|c|c|c|}
\hline & A. & B. & C. & D. & E. & F. & G. & $\mathrm{H}$. \\
\hline & 贸 & 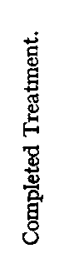 & 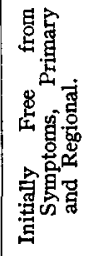 & 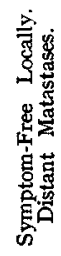 & 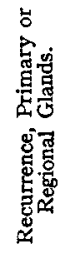 & 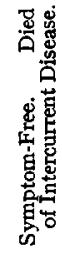 & 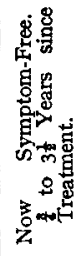 & 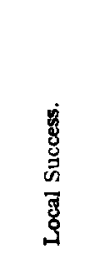 \\
\hline Epipharynx & 4 & 2 & $\mathbf{2}$ & - & - & - & 2 & $2: 2$ \\
\hline Tonsil & 24 & I9 & II & I & 4 & - & 8 & $9: 19$ \\
\hline Base of the tongue & 16 & r3 & 6 & $\mathbf{I}$ & - & 2 & 7 & $10: 13$ \\
\hline $\begin{array}{l}\text { Vallecula } \\
\text { Lateral and posterior wall }\end{array}$ & II & I0 & 6 & - & 4 & I & 3 & $4: 10$ \\
\hline mesopharynx $\ldots$ & 4 & 2 & 2 & - & I & - & 2 & $2: 2$ \\
\hline Epiglottis .. $\quad$. & 4 & 4 & 3 & $\mathbf{I}$ & 2 & - & - & $\mathrm{I}: 4$ \\
\hline Aryepiglottic fold & 7 & 7 & 6 & I & I & I & 3 & $5: 7$ \\
\hline Arytenoid. & 4 & 4 & 3 & 2 & 一 & 一 & 2 & $4: 4$ \\
\hline Sinus pyriformis ... & 44 & $3^{8}$ & 17 & 4 & - & 7 & 7 & I8: 38 \\
\hline 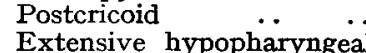 & 2 & I & - & & $\mathbf{I}$ & & & $0: \mathbf{I}$ \\
\hline $\begin{array}{c}\text { Extensive hypopharyngea } \\
\text { growth } \ldots\end{array}$ & 9 & 5 & 2 & - & - & 2 & - & $2: 5$ \\
\hline Intrinsic laryngeal & I5 & II & 7 & - & - & $\mathbf{r}$ & 6 & $7: 11$ \\
\hline
\end{tabular}




\section{Malignant Disease of Larynx and Pharynx}

success is calculated, as before, as the ratio of the sum of columns $\mathrm{D}, \mathrm{F}_{1}, \mathrm{~F}_{2}$ and $\mathrm{G}$ to column $\mathrm{B}$ - " Cases concluded treatment". The table shows that the figure for local success has undergone no appreciable change during two years - a fact

TABLE III. (Compiled Sept., I934.)

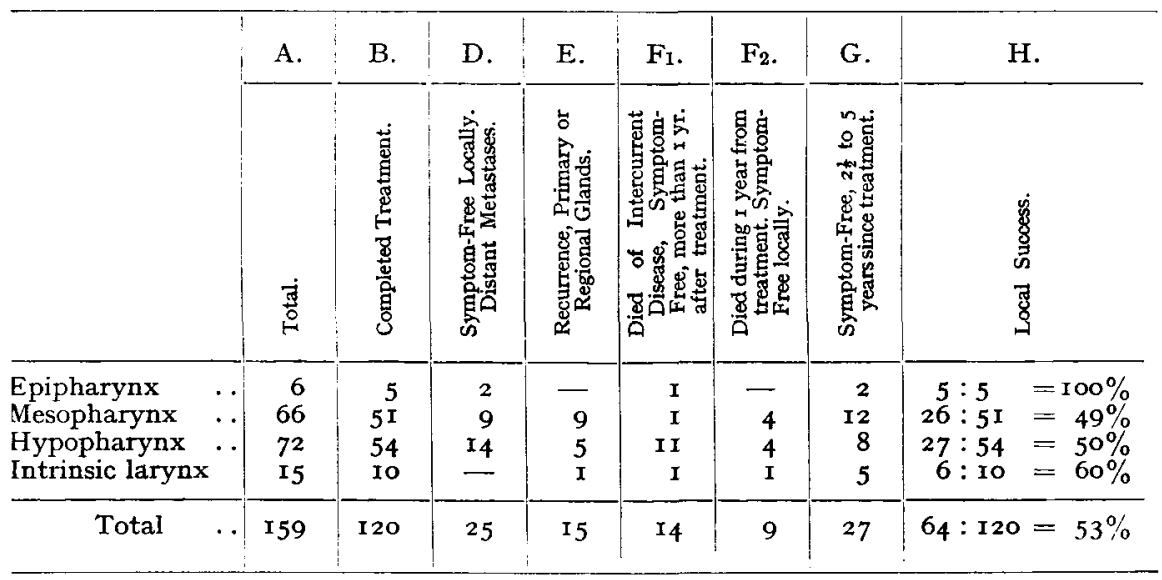

TABle III $a . \quad$ (Compiled Sept., I932.)

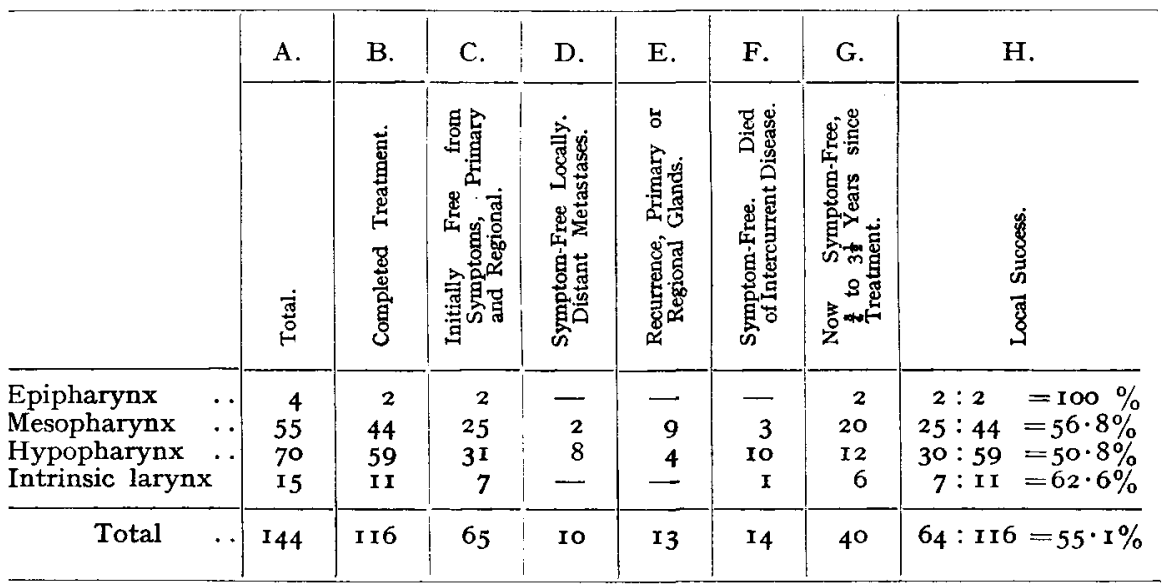

corresponding to the extreme scarcity of a local recurrence after the first six to nine months after treatment. The figure of 53 per cent. is impressive but, after an observation of a period of two and a half years, the absolute and relative rates must be given (Table IV). 


\section{A. Zuppinger and R. Stewart-Harrison}

In spite of a primary local success in the neighbourhood of 50 per cent. the two-year figures for absolute and relative freedom from symptoms are but 17 per cent. and 26 per cent. respectively. The corresponding figures for a three-year observation period are I7 per cent. and 22 per cent. These figures are not large, but they represent the true position of the radiotherapy of malignant disease of the larynx and pharynx. They refer to unselected material. No case is regarded as being too advanced to be sent to us for treatment. We regard no case as too advanced for a therapeutic effort. The chief reason for the unsatisfactory figures is not the occurrence of recurrences and not the difficulty of achieving a primary success:

Table IV.

Absolute and Relative Healing Rates-Observation Period $2 \frac{1}{2}$ YEARS.

\begin{tabular}{|c|c|c|c|}
\hline & Total. & $\begin{array}{l}\text { Relative Healing } \\
\text { in number, } \%\end{array}$ & $\begin{array}{l}\text { Absolute Healing } \\
\text { in number, } \%\end{array}$ \\
\hline Epipharynx & 6 & $2: 5=40$ & $2: 6=33$ \\
\hline Mesopharynx & 66 & $\mathrm{I} 2: 5 \mathrm{I}=24$ & $\mathbf{I 2}: 66=\mathbf{1 8}$ \\
\hline Hypopharynx .. & 72 & $8: 54=15$ & $8: 72=$ I I \\
\hline Intrinsic larynx & 15 & $5: 10=50$ & $5: I_{5}=33$ \\
\hline Total & 159 & $27: 120=26 \%$ & $27: 159=17 \%$ \\
\hline
\end{tabular}

ABSOLUTE RATE $=\frac{\text { Number Living, Symptom-Free }}{\text { Number Seen }}$
RELATIVE RATE $=\frac{\text { Number Living, Symptom-Free }}{\text { Number Treated }}$

in sixty-three cases that became free from disease locally and regionally after treatment we saw a recurrence only fifteen times and only one of these occurred after the first year. In the other forty-eight cases death occurred, when the patient showed no clinical signs of neoplasm, either locally or in the regional glandular area. In a large proportion of these cases this clinical condition was confirmed at autopsy. It is not, however, justifiable to regard these forty-eight cases as being successful. Columns $F_{1}$ and $F_{2}$ in Tables II and III show that no less than nine cases died of intercurrent disease, usually some form of circulatory failure, possibly combined with an infection, during the first half-year after treatment. Some of these cases, at any rate, must be regarded as being " treatment " deaths in the sense that the lowering of the general condition 


\section{Malignant Disease of Larynx and Pharynx}

following the treatment made the patients less resistant to these affections. Equally, the lowering of the general condition due to treatment, particularly during treatment, may have predisposed the patients towards the development of distant metastases. The intercurrent deaths occurring after the first year may, we think, be regarded as strictly intercurrent and as having no connection with the original malignant disease or with the treatment.

It is not possible to compare these absolute results with other statistics, for no absolute figures for the results of treatment of malignant disease of the larynx and pharyn $\mathrm{x}$ in unselected cases have been published by other workers. All those which are available refer to more or less selected material.

Accepting the consequences of these figures, we are convinced that we have obtained an improvement in subsequent cases and that we shall continue to attain improvement by attention to the following points :

I. General condition of the patient.

2. Suppression of distant metastases.

3. Advance in the treatment of recurrences, more particularly of residual tumours and, above all, in the treatment of glandular metastases.

With these purposes in view the following modifications in the technique of radiotherapy have been adopted. The tube tension has been increased from 170 to 180 kilovolts. The tube current has been increased from 3 to 4 milliampéres. The filter has been increased from I mm. Al $+\mathrm{I} \mathrm{mm}$. Cu to I mm. $\mathrm{Al}+2 \mathrm{~mm}$. $\mathrm{Cu}$ : the resulting half-value layer is increased to $\mathrm{I} \cdot 8 \mathrm{~mm}$. $\mathrm{Cu}$. The focus-skin-distance exceeds $70 \mathrm{~cm}$. The radiation intensity is 2.5 Röntgens per minute measured in air (as before).

Only rarely are more than two fields chosen for radiation, and these are made correspondingly large in an attempt to increase the dose in the metastatic area. Corresponding to the larger fields, the dose per single sitting is very often reduced from the former customary $180 \mathrm{r}$ to $150 \mathrm{r}$ or even less. Should the general condition of the patient be indifferent, even lower figures for the single treatment are chosen. The time for the total treatment is thereby increased : very frequently a month or even more will be required for the completion of treatment. Corresponding to this increase of time, an increase in the total 


\section{A. Zuppinger and R. Stewart-Harrison}

dose is possible. The total dose now reaches 7,000 to $8,000 \mathrm{r}$ on two fields.* In an effort to delay and reduce the skin reaction consequent upon this technique we have experimented with infra-red radiation during the last week of X-ray radiation - the results have been encouraging. As before, a treatment is given twice daily except on Saturdays and Sundays. The clinical course of treatment is not modified in principle, but the modifications in technique have led to a reduction in the severity of the reactions, with a corresponding increase in their duration. The changes described are directed primarily to the preservation of the patients' general condition and, consequently, to the suppression of distant metastases and intercurrent disease. Further, an increase in the total dose within the margins of safety is permitted. We have described the technique in several publications and we wish to emphasize once more that the only possibility of success lies in a course of treatment exactly suited to each individual case. Any attempt to adhere to a particular schematic plan will fail. The individual variations are applicable firstly to variations in the general condition of each patient and are, therefore, possible only when the patient is under the fullest clinical control of the radiologist conducting the treatment. Secondly, certain other considerations are applicable to various localizations of the neoplasm.

\section{Epipharynx}

The vast majority of tumours of the epipharynx fall into the group of highly radiosensitive neoplasms. Thus in our material of six cases there were two lymphoepithelial carcinomata, one transitional cell carcinoma, one carcinoma of uncertain nature, one lymphosarcoma, and one embryonal sarcoma. All the tumours were characterized by extensive metastases. The radiation fields were therefore chosen to be very large and the total dose does not reach the maximum. This reduction is made possible by the high sensitivity of the neoplasms.

\section{Tonsillar Region}

Sarcoma of the tonsil is relatively frequent. The reported material contains six cases. These sarcomata are, in general, radio-sensitive, although exceptions are found. In general it is

* The determination of the surface $r(r / 0)$ has been given up : the calculation is unreliable on account of irregular fields and varying angles of incidence of the rays. All doses are given in Röntgens measured in air ( $\mathrm{r}$ or $\mathrm{r} / \mathrm{l}$ ). 


\section{Malignant Disease of Larynx and Pharynx}

permissible to reduce the total dose and we have noticed, as was pointed out in the first communication, that in spite of the reduction in total dose a strong reaction of the mucous membrane has developed. It seems that those patients who show sensitive tumours have also a sensitive mucous membrane. The carcinomata of the tonsil and tonsillar region show somewhat disappointing results. Without exception the tumour regresses very considerably during the course of treatment, but a small residual tumour in the angle between the fauces and the tongue often remains after treatment. The treatment of this residual tumour is difficult. It has been discussed in other publications (Stewart-Harrison, Zuppinger) in some detail. Two methods are available: surface application with radium with Berven's applicator, or electrocoagulation with the implantation of one or two radium needles. The first method is more suitable for small residual tumours, the second may be accompanied by a small radiumnecrosis which, atthough unpleasant, will heal, and is more suitable for larger badly defined infiltrations. In cases in which the second method of supplementary treatment is used, ligature of the carotid is essential.

\section{Base of the Tongue}

Tumours of the base of the tongue are usually carcinomata. The same principles of treatment as those employed in the case of tonsillar carcinoma apply. Emphasis must be laid on the necessity for the radical treatment of residual growth.

\section{Vallecula}

The less differentiated forms of carcinoma are the commonest tumours of the vallecula. The tumours are correspondingly radiosensitive and the primary result is usually good. Metastasis from tumours of the vallecula is often extensive: in one-third of our cases metastases were present on both sides. "We have observed two cases with metastases in the œsophageal mucous membrane from carcinoma of the vallecula. Distant metastases are correspondingly frequent.

\section{Epiglottis}

Tumours of the epiglottis are characterized by the inevitable infiltration of the epiglottic cartilage with consequent difficulty in eradicating the primary tumour. A high total dose must be applied. 


\section{A. Zuppinger and R. Stewart-Harrison}

Aryepiglottic Fold

Tumours of the aryepiglottic fold are relatively favourable. They are usually of the more radiosensitive type and the situation of the tumour conduces to diagnosis in an earlier stage. Further infiltration of the cartilage is relatively late since the cartilage does not lie in the immediate neighbourhood.

\section{Arytenoid}

The remarks made in the case of tumours of the aryepiglottic fold are also applicable to the arytenoid region.

\section{Sinus Pyriformis}

Tumours of the sinus pyriformis are invariably carcinomata. In the early stage they produce only trifling symptoms and when the patients come for treatment a comparatively advanced condition is usually found. The thyroid cartilage is almost invariably infiltrated and an infection is the rule. In three cases dying before treatment could be started or during the first few days of treatment, we found an extensive necrosis of the cartilage and larynx. A considerable odematous swelling of the laryngeal mucous membrane usually accompanies tumours of the sinus pyriformis. Radiation treatment can lead to an increase in this odema which may make tracheotomy necessary. In this case low tracheotomy must be performed. Further, the cannula should, if at all possible, be dispensed with as soon as the tumour has regressed sufficiently to permit the patient to breathe. Cases in which the tracheotomy is retained during the reaction have a very bad prognosis.

We have, nevertheless, been successful in a large number of cases in avoiding the threatened tracheotomy. In these cases treatment is commenced with small doses of $120 \mathrm{r}$ but once daily. As soon as the oedema has been reduced the intensity of treatment is increased. The palliative effect, should it be possible to complete treatment, is usually good in cases of tumour of the sinus pyriformis and the number of permanent tracheotomies and gastrostomies in our material is negligible.

\section{Larynx (Intrinsic)}

Mutatis mutandis, the same considerations apply as in the case of tumours of the sinus pyriformis. Tumours of the false cord are highly radiosensitive (Coutard).

$$
728
$$




\section{Malignant Disease of Larynx and Pharynx}

\section{Treatment Indications (Zürich)}

Radiological treatment is the treatment of choice in all malignant tumours of the epi-, meso- and hypopharynx. Only those tumours of the intrinsic larynx in which a small radioresistant tumour is localized to one true cord are, in our opinion, suitable for operation by excision (laryngofissure) with excellent hope of recovery and no permanent disadvantage to the patient. Theoretically we consider a case of carcinoma of the larynx characterized by very extensive infiltration of the cartilage from a highly radio-resistant epithelioma in which total laryngectomy would be the treatment of choice. We have not actually carried out this treatment. In a case in which it was suggested the patient refused operation. At present, in conjunction with the otological clinic in Zürich (Prof. Nager, who has co-operated with us for many years in the development of this form of treatment of the malignant disease of the larynx and pharynx) we are treating all other cases of intrinsic laryngeal carcinoma with protracted-fractional X-rays.

\section{Conclusions}

Since the time of the first communication there has been but little addition to the literature which is directly applicable to these cases. Douglas Webster, who has adopted the method recently, has had encouraging early results and is continuing with the method. At the Fourth International Congress of Radiology, malignant disease of the larynx and pharynx was the subject of extensive discussion, during which it became clear that the treatment of these affections lay between external $\mathrm{X}$-ray radiation in highly fractionated doses and external radium. The value of the protraction of the individual dose was again discussed in detail, opinions were divided but, in our opinion, the considerations advanced by Coutard demanding an intensity of 2 to $3 \mathrm{r}$ per minute must be respected. In the same contribution Coutard discussed in detail the results of treatment in cases of epithelioma limited to the hypopharynx. He pointed out that the good primary results are counteracted, not by the development of a local recurrence, but by the development of distant metastases many years after treatment. He reports three cases of distant metastases among fourteen patients more than five years after the conclusion of treatment, and two cases among ten patients reaching the seventh year after 


\section{A. Zuppinger and R. Stewart-Harrison}

treatment. In his material, no less than 52 per cent. of patients who were free from symptoms locally three years after treatment, died of distant metastases before the end of the eighth year. Coutard himself concludes that these figures can be improved only by closer individualization of the treatment and suggests a reduction of the intensity of radiation and an increase in the time taken for complete treatment.

We have not sufficient experience of the technique to enter in detail upon the radium treatment of these conditions. The results in cases of epithelioma in the neighbourhood of the fauces and the base of the tongue are according to Berven, Pfahler, and others not inferior, and in some special cases superior to the results of the protracted-fractional treatment. The cost of the necessary quantity of radium should not limit further research in this direction.

Our own experience and the experience of others does not lead to the conclusion that the protracted-fractional X-ray treatment is a universal cure for cancer. Not even in cases of malignant disease of the larynx and pharynx can we be content with these results. We have been experimenting for some years with similar forms of treatment, in principle, for carcinoma of the œsophagus : here again the primary result is satisfactory, but the late results leave much to be desired. We are, however, convinced that this technique represents an advance in the radiation therapy of cancer of the upper air passages and that the results, in unselected material, are equal to or better than those of surgery and are obtained without the inevitable mutilation consequent upon "excision" operations in this region.

A further communication will be published in due course.

\section{Summary}

I. The paper represents a "follow up " investigation of a number of cases of carcinoma of the larynx and pharynx that formed the subject of a provisional report in this Journal in November, I932.

2. One hundred and fifty-nine cases are considered. Of these, r2o completed treatment. At the present moment 27 are living free from all disease two and a half to five years after treatment. Nine died of intercurrent disease free from symptoms locally during the first half-year after treatment. Fourteen died of intercurrent disease more than one year after 


\section{Malignant Disease of Larynx and Pharynx}

treatment. In 25 cases distant metastases developed by freedom from local and regional disease. Fifteen recurrences were seen, only one of which occurred after the first year. After an observation period of two and a quarter years the local success is 53 per cent., the relative success $26 \mathrm{per}$ cent. and the absolute success I7 per cent.

3. Certain modifications of the technique based on experiences of recent years have been recounted.

4. We accept protracted-fractional treatment as the treatment of choice in all cases of malignant disease of the pharynx and in most cases, if not all, of carcinoma of the larynx.

\section{REFERENCES}

Stewart-HARRISON, R., "Malignant Disease of the Larynx and Pharynx," Journ. of Laryngol. and Otol., 1932, xlvii., 725 (References up to 1932).

Webster, Douglas G., "The protracted-fractional X-ray method (Coutard) in the Treatment of Cancer of the Larynx," Proc. of the Royal Society of Medicine, I934, xxvii., 903.

Schinz, H. R. and Zuppinger, A., " Bericht über die Zürcher Erfahrungen mit protrahiert-fraktionierter Röntgenbestrahlung der Jahre 1929-32 bei Tumoren der oberen Luft-und Speisewege," Strahlenther., I934, 1., 237.

Perussia, F.

COUTARD, $\mathrm{H}$.

Berven, E.

FINZI, N. S.

Pfahler, G.

LENZ, M.

FRIEDMANN, M. Sectional reports to the IVth Internat. Congress
EDLING, L.

MARTIN, H.

of Radiology. Ibidem.

LAMBADARIDES, R.

Die vorliegende Arbeit bildet eine Ergänzung zu derjenigen, die vor 2 Jahren in dieser Zeitschrift erschienen ist. Die Verfasser besprechen die Ergebnisse der protrahiert-fraktionierten Röntgenbestrahlung nach einer Beobachtungsdauer von 2-5 Jahren. Die Resultate werden zu Vergleichszwecken tabellarisch zusammengestellt.

Es werden Einzelheiten gegeben über die Tumoren, die in den verschiedenen Abschnitten der obern Luftwege gefunden wurden und die für jeden derselben nötige Behandlungsart. Die Verfasser kommen zur Schlussfolgerung, dass diese Behandlungsweise kein 


\section{A. Zuppinger and R. Stewart-Harrison}

Universalheilmittel gegen den Krebs darstellt. Obwohl in vielen Fällen die Primärgeschwülste zum Verschwinden gebracht werden können, liegt die Gefahr nicht in lokalen Rezidiven, sondern in der Entstehung von Fernmetastasen, selbst viele Jahre nach der Bestrahlung.

Die Verfasser haben I20 Fälle untersucht. Von diesen zeigten $53 \%$ einen lokalen, $26 \%$ einen relativen und $I 7 \%$ einen vollständigen Heilungserfolg nach etwa $2 \frac{1}{4}$ Jahren. Sie hoffen in absehbarer Zeit weitere Ergebnisse veröffentlichen zu können.

Cet article est un supplément à celui publié dans ce même journal il y a deux ans. Cette communication a trait aux résultats des traitements prolongés et fractionnés par les Rayons $\mathrm{X}$, après une période d'observation variant de deux à cinq ans, et ceux-ci sont présentés sous forme de tableaux, pour permettre la comparaison.

Les auteurs donnent des détails sur les tumeurs que l'on rencontre dans les diverses portions des parties supérieures de l'appareil respiratoire, et du traitement nécessité par chacune d'elles.

Les auteurs concluent que ce traitement n'est pas un procédé universel pour le cancer et que, bien qu'il amène la disparition de tumeurs primitives dans de nombreux cas, le danger consiste, non pas dans des récidives locales, mais dans des métastases lointaines plusieurs années après le traitement.

Les auteurs ont étudié cent-vingt cas, dont cinquante-trois pour cent ont été un succès local, vingt-six pour cent un succès relatif, et dixsept pour cent un succès complet, depuis vingt-sept mois.

Ils espèrent publier la suite des résultats en temps voulu. 